Original Article

\title{
Effect of backpack shoulder straps length on cervical posture and upper trapezius pressure pain threshold
}

\author{
Osama Ragaa Abdelraouf, PhD ${ }^{1)}$, Hamada Ahmed Hamada, PhD ${ }^{1 *}$, Ali Selim, $\mathrm{PhD}^{1)}$, \\ WAEl Shendy, PhD ${ }^{1)}$, Hoda ZaKaria, PhD ${ }^{1)}$ \\ 1) Faculty of Physical Therapy, Cairo University: 7El Zayyat Street, Dokki, Giza 12611, Egypt
}

\begin{abstract}
Purpose] This study was performed to investigate the effect of the length of backpack shoulder straps on upper trapezius muscle pain threshold and craniovertebral angle. [Subjects and Methods] There were 25 participants, with ages from 15 to 23 years old. Upper trapezius pain threshold and craniovertebral angle were measured for all subjects without the backpack then re-measured after walking on a treadmill for 15 min under 2 conditions: 1) wearing a backpack with short straps; and 2) wearing a backpack with long straps. [Results] there was a significant reduction in upper trapezius pain threshold and craniovertebral angle while carrying a backpack with long shoulder straps, compared to use of a backpack with short shoulder straps or no backpack. [Conclusion] A backpack with short straps is less harmful than a backpack with long straps. This result should be considered in ergonomic design of backpacks to reduce the incidence of various physiological and biomechanical disorders.

Key words: Backpack, Shoulder straps, Cervical posture
\end{abstract}

(This article was submitted Feb. 27, 2016, and was accepted May 14, 2016)

\section{INTRODUCTION}

Backpacks are a commonly in school systems ${ }^{1)}$. There are various types of bags such as shoulder bags and backpacks, and various styles of carrying a bag. People use these different types of bags to carry the things they require in their daily lives. While carrying a bag and walking, the body is subjected to physical stress owing to the weight of the bag, and the body is either mechanically or physiologically influenced, which affects dynamic balance and changes the posture of the body 2,3 . Carrying a backpack in an incorrect manner can cause various biomechanical, physiological and neuromuscular disorders that may reduce physical performance ${ }^{4,5)}$. An ideal bag weight and space between the shoulder straps have been recommended ${ }^{6,7)}$. Asymmetry of weight distribution in both shoulder straps may cause a spinal deformity with gait abnormalities and scoliosis ${ }^{1,2)}$. Carrying weight on one shoulder increases energy consumption and leads to alteration in the electromyogram of both arms and legs muscles ${ }^{8,9)}$. If carrying weight on one side continues, the body involuntarily compensates by deviating the trunk in the opposite direction to correct the imbalance caused by an external force creating abnormal posture ${ }^{9}$. Excessive weight will increase the load on the spine and shoulders and it may cause changes in the spine curvature ${ }^{4)}$. Scapular position $^{1)}$ and electromyogram activities of the trunk and lower extremities muscle ${ }^{3,8)}$ may be affected by a change in the space between the backpack shoulder straps. Lengthening or weakening of the upper trapezius can also lead to scapular depression syndrome and pain in the upper trapezius muscle ${ }^{6}$.

Researchers have studied various backpack types and designs with the aim of preventing injuries associated with prolonged load carrying ${ }^{10)}$. Few studies investigated the effect of the spacing of backpack shoulder straps on cervical muscle activity, acromion angle, scapular distance and upper trapezius pain threshold after walking with a backpack. There is a lack of literature on proper length and level of backpack shoulder straps. Therefore, the purpose of this study was to investigate

\footnotetext{
*Corresponding author. Hamada Ahmed Hamada (E-mail: hamadabiomechanics@gmail.com)

(C)2016 The Society of Physical Therapy Science. Published by IPEC Inc.

This is an open-access article distributed under the terms of the Creative Commons Attribution Non-Commercial No Derivatives (by-nc-nd) License $<$ http://creativecommons.org/licenses/by-nc-nd/4.0/>.
} 
the effect of the length of backpack shoulder straps on upper trapezius pain threshold and cervical posture as measured by the craniovertebral angle.

\section{SUBJECTS AND METHODS}

Twenty-five males were assigned to one group and gave signed informed consent to participate in the study. Their mean age, height and weight were $(19 \pm 3)$ years, $(78.8 \pm 6) \mathrm{kg}$ and $(173 \pm 8) \mathrm{cm}$, respectively. The subjects had no musculoskeletal disorder or pain in the upper extremities in the prior 6 months. This study was approved by the local Research Ethical Committee with number: P.T.REC/012/0014. The study was designed as an experimental single control trial.

The experiment was clearly explained to all participants. Weight and height were measured using a scale. Upper trapezius pain threshold and craniovertebral angle were measured for all subjects without the backpack (Delsey, France) then remeasured after walking on a treadmill for 15 min under 2 conditions: 1) wearing a backpack with short straps and 2) wearing a backpack with long straps. Pain threshold of the bilateral upper trapezius was measured before the experiment by using a pressure algometer dynamometer (FAB148; Fabrication Enterprises, White Plains, NY, USA) at the upper trapezius trigger point area located at the measured midpoint between the acromion process and the spinous process of T1.

The craniovertebral angle is formed by the intersection of a horizontal line through the spinous process of $\mathrm{C} 7$ and a line from the tragus of the ear. This is believed to provide an estimation of neck on upper trunk positioning. A small angle indicates forward head posture ${ }^{11}$. Clothing was rearranged so that shoulders were exposed. With the subjects in standing posture, adhesive markers were placed on 2 anatomical landmarks (tragus of the ear and spinous process of the 7th cervical vertebra). Subjects were asked to stand comfortably with their arms by their sides with normal posture. They were asked to place their weight evenly on both feet. The lateral malleoli were placed between parallel lines, perpendicular to the frontal planes. The subjects looked directly ahead. The position was then checked prior to taking a photograph. The photograph was taken within $5 \mathrm{sec}$ after attaining the position. Sony 8 mega pixels digital camera (Sony Corporation, Tokyo, Japan) was attached to an adjustable tripod stand and the camera height adjusted to the shoulder level of participants, the camera was placed $50 \mathrm{~cm}$ from the subject's right side and positioned perpendicular to the ground ${ }^{11)}$. The photographs of the subjects were taken in random order. Subjects were encouraged to relax and move about after each photograph. Photographs were analyzed with digital software (Kinovea organization, Paris, France, 2 D software version 0.7.10).

The backpack used in this study itself weighted $0.9 \mathrm{~kg}$. The space between the shoulder straps in the backpack was adjusted to be $20 \mathrm{~cm}^{1}$ ). The weight of the bag was $15 \%$ of the individual's body weight ${ }^{7)}$. The bottom end of the backpack was at the level of T12 with short shoulder straps and at S1 with long shoulder straps. Each individual was asked to walk on the treadmill for $15 \mathrm{~min}$ at a speed of $2 \mathrm{~km} / \mathrm{h}^{1}$. On the first day, the individual randomly used one of the 2 load-carrying styles; after $24 \mathrm{~h}$ the same individual used the other style. Pain sensitivity and craniovertebral angle were measured after 15 min walking in both conditions. The selection of shoulder straps length was randomized using sealed envelopes to avoid a learning effect.

Data analysis was performed using (SPSS, Inc. Chicago, IL, USA) program version 18 for Windows. The sample size (25 participants) was calculated to yield an $80 \%$ power and $\alpha=0.05$. Prior to final analysis, data were screened for normality assumption, and presence of extreme scores. This exploration was done as a pre-requisite for parametric calculation of the analysis of differences and of relationship measures. Repeated measure multivariate analysis of variance (MANOVA) was used to statistically compare the upper trapezius pressure pain threshold and craniovertebral angle obtained during 3 backpack conditions. Post hoc testing was used to identify significant differences.

\section{RESULTS}

There was a statistically significant difference in upper trapezius pain threshold among the 3 different conditions (without backpack, backpack with short straps, and backpack with long straps) $(\mathrm{F}=134.005, \mathrm{p}<0.05)$. A multiple pairwise comparison test (post hoc test) revealed that there was a statistically significant reduction in the upper trapezius pain threshold in the backpack with long straps condition compared with the without backpack and backpack with short straps conditions $(\mathrm{p}<0.05)$. In addition, there was a statistically significant reduction in the upper trapezius pain threshold in the backpack with

Table 1. Dependent variables in participants while wearing a backpack with short straps; or a backpack with long straps and without a backpack

\begin{tabular}{lccc}
\hline & Without backpack & $\begin{array}{c}\text { Backpack with short } \\
\text { straps }\end{array}$ & $\begin{array}{c}\text { Backpack with long } \\
\text { straps }\end{array}$ \\
\hline Upper trapezius pain threshold $\left(\mathrm{kg} / \mathrm{cm}^{2}\right)$ & $3.7 \pm 1.0$ & $4.3 \pm 1.2^{*}$ & $5.8 \pm 1.2^{\# \#}$ \\
Craniovertebral angle (degrees) & $39.4 \pm 2.3$ & $44 \pm 1.7^{*}$ & $47 \pm 2^{\# ¥}$ \\
\hline
\end{tabular}

*significant $(\mathrm{p}<0.05)$ difference between without backpack and backpack with short straps, ${ }^{\#}$ significant $(\mathrm{p}<0.05)$ difference between backpack with short straps and backpack with long straps, ${ }^{¥}$ significant $(\mathrm{p}<0.05)$ difference between without backpack and backpack with long straps. 
short straps compared with the without backpack condition $(\mathrm{p}<0.05)$. There was also a statistically significant difference in the craniovertebral angle among the 3 different conditions $(\mathrm{F}=31.442, \mathrm{p}<0.05)$. A multiple pairwise comparison test (post hoc test) revealed that there was a statistically significant reduction in the craniovertebral angle in the backpack with long straps condition compared with the without backpack and backpack with short straps conditions $(\mathrm{p}<0.05)$. In addition, there was a statistically significant reduction in the craniovertebral angle in the backpack with short straps compared with the without backpack condition $(\mathrm{p}<0.05)$ (Table 1$)$.

\section{DISCUSSION}

This study revealed that subjects assume a forward head posture (indicated by a decrease in craniovertebral angle) when carrying a backpack with long straps more than when using short straps. There was a significant difference in upper trapezius pain threshold and craniovertebral angle value with different backpack shoulder strap lengths. Thus it can be concluded that carrying a backpack with long straps would alter the compensatory head position and may result in pain and other anomalies associated with altered posture.

Mackie et al. ${ }^{12)}$ showed that manipulation of backpack weight, and shoulder strap length had a strong effect on shoulder strap tension and shoulder pressure. Backpack weight had the greatest effect on shoulder strap tension and shoulder pressure while shoulder strap adjustment had the next greatest influence. Therefore, this study investigated the effect of backpack shoulder strap length on upper trapezius pain threshold and craniovertebral angle. The different lengths of backpack shoulder straps changed the backpack load transmission. While using long shoulder straps, the area of contact between the backpack and the back is small with the backpack load concentrated on both shoulders. Conversely, with short shoulder straps the area of contact between the backpack and back is large so that an increase in the surface area will lead to a decrease in the stress on the shoulders. Moreover, the back will dissipate some of the forces, which leads to reduction in the load on the shoulders. From a biomechanical point of view, the torque produced while the shoulder straps are long is greater than the torque produced while the shoulder straps are short, due to an increase in the angle of pull and in the backpack weight moment arm. The upper trapezius pressure pain threshold was also significantly decreased with the long shoulder straps compared to that for the short shoulder straps. It was surmised that the pain sensitivity in the upper trapezius might be increased by scapular depression and downward rotation, causing overstretching of the upper trapezius ${ }^{12}$. Scapular depression syndrome is associated with lengthening or weakening and a lower pressure pain threshold in the UT muscle ${ }^{12}$. A prolonged time in the depressed scapular position, in particular, may lead to chronic upper trapezius pain ${ }^{12)}$. A backpack with long shoulder straps places a lower muscular requirement on the cervical muscles, but may cause an increase in the compressive component of backpack weight, in addition to scapular depression. The long-term outcome might be chronic upper trapezius pain. Backpack weight had the greatest influence on shoulder straps tension and shoulder pressure as the weight of the backpack increased the strap tension and shoulder pressure also increased. When the shoulder straps were loose, the tension and pressure under the shoulder straps decreased ${ }^{13)}$. As the torque produced while the shoulder straps are long is greater than the torque produced while the shoulder straps are short, shoulder strap tension and shoulder pressure increase.

The study found evidence to accept one common _"rule-of-thumb"_ for load carrying, backpacks should be positioned high on the trunk at T12 not L3. The findings in the current study were supported by those of Kim et al. ${ }^{14)}$, who believed that carrying a backpack in the upper position may lead to safer use, and may help prevent musculoskeletal discomfort in those who regularly use a backpack. The study findings suggested that adjusting the backpack position, by fastening the shoulder strap, is a useful strategy for the prevention of musculoskeletal problems in school-age children. Lower load placement produces more forward body lean, adding weight to the front half of the feet. Moreover, previous studies have reported that forward leaning of the upper trunk increases to a greater extent, when subjects carry a backpack in a lower position, using a longer shoulder strap ${ }^{15,16)}$. Shoulder straps should be adjusted so that the pack fits close to the upper part of the back. The further the backpack load is from the upper back, the more it pulls the body backward and strains muscles between the shoulders ${ }^{17}$.

Placement of a backpack is a factor that can also potentially alter the design of a backpack. Based on the results of 4 studies, low backpack placement leads to less postural deviation and postural sway ${ }^{5}{ }^{18-20)}$. One of these 4 studies was conducted on adults and the other 3 on adolescents. Three of the studies showed that load placement does not have any influence on gait and posture. One study recommended that for carrying more than $15 \%$ of body weight, low load placement should be avoided $^{21)}$. Other studies investigated the effect of load positioning on energy and oxygen consumption, pain, contact pressure and pulmonary function; however, due to limited evidence no conclusions can be drawn ${ }^{22}$.

A study by Brackley et al. ${ }^{5}$ evaluated changes in trunk forward lean, craniovertebral angle, and spinal lordosis angle that occurred with high, medium and low load placement during standing and walking in children. The study concluded that low load placement in the backpack produced a fewer changes in craniovertebral angle and spinal lordosis angle. In addition, Joseph and Sengupta ${ }^{23)}$, investigated the effect of the position of a backpack on physiological cost and perceptual responses of university students. Each participant carried books weighing $15 \%$ of their body weight in a backpack with upper back vs. lower back placement and no load conditions. For the high backpack position, the top of the bag was leveled at the shoulder line, and for the low backpack position the bottom of the backpack was leveled at the L5 lumbar vertebra. The results indicated that wearing the backpack on the upper back might impose additional physical stress on male university 
student. Moreover, low load placement (at the spinal level of L3) was recommended by Grimmer et al ${ }^{21)}$. When considering horizontal displacements of various anatomical landmarks with only a rested standing posture and $10 \%$ body weight loads, backpacks positioned at $\mathrm{T} 7$ produced a larger forward (horizontal) displacement of all the anatomical points than when positioned at (T12 and L3). In contrast to those in children, adult backpack studies have found that high load placement minimizes postural adaptations, indicating that adult findings cannot be directly transferred to children. Additionally, Frank et al. ${ }^{24)}$ found that the forces on the shoulder and back were minimized with low load placement; however, postural analysis found less changes with high placement. Mackie et al. ${ }^{12)}$ found that load weight, use of a waist belt and longer strap lengths resulted in less shoulder pressure, thus advocating lower load placement. Other researchers have advocated higher load placements, as forward lean is less than with low placements.

This study set out to determine the proper length of shoulder straps. The results of this study indicate that short straps are better than long straps. For-optimal use and ergonomic design, the backpack must be carried with a load equal 10-15\% of body weight, the space between the shoulder straps must be narrow and the length of the straps must be short at the level of T11-T12.

\section{REFERENCES}

1) Kim MH, Yoo WG: Effect of the spacing of backpack shoulder straps on cervical muscle activity, acromion and scapular position, and upper trapezius pain. J Phys Ther Sci, 2013, 25: 685-686. [Medline] [CrossRef]

2) Lucas-Cuevas AG, Pérez-Soriano P, Bush M, et al.: Effects of different backpack loads in acceleration transmission during recreational distance walking. J Hum Kinet, 2013, 37: 81-89. [Medline] [CrossRef]

3) Ozgül B, Akalan NE, Kuchimov S, et al.: Effects of unilateral backpack carriage on biomechanics of gait in adolescents: a kinematic analysis. Acta Orthop Traumatol Turc, 2012, 46: 269-274. [Medline] [CrossRef]

4) Son H: The effect of backpack load on muscle activities of the trunk and lower extremities and plantar foot pressure in flatfoot. J Phys Ther Sci, 2013, 25: 1383-1386. [Medline] [CrossRef]

5) Brackley HM, Stevenson JM, Selinger JC: Effect of backpack load placement on posture and spinal curvature in prepubescent children. Work, 2009, 32: 351-360. [Medline]

6) Blacker SD, Fallowfield JL, Bilzon JL, et al.: Neuromuscular impairment following backpack load carriage. J Hum Kinet, 2013, 37: 91-98. [Medline] [CrossRef]

7) Forjuoh SN, Little D, Schuchmann JA, et al.: Parental knowledge of school backpack weight and contents. Arch Dis Child, 2003, 88: 18-19. [Medline] [CrossRef]

8) Lindner T, Schulze C, Woitge S, et al.: The effect of the weight of equipment on muscle activity of the lower extremity in soldiers. ScientificWorldJournal, 2012, 2012: 976513. [Medline] [CrossRef]

9) Cho SH, Lee JH, Kim CY: The changes of electromyography in the upper trapezius and supraspinatus of women college students according to the method of bag-carrying and weight. J Phys Ther Sci, 2013, 25: 1129-1131. [Medline] [CrossRef]

10) Azevedo DC, de Lima Pires T, de Souza Andrade F, et al.: Influence of scapular position on the pressure pain threshold of the upper trapezius muscle region. Eur J Pain, 2008, 12: 226-232. [Medline] [CrossRef]

11) Sahrmann SA: Diagnosis and treatment of movement impairment syndromes. St. Louis: Mosby, 2002.

12) Mackie HW, Stevenson JM, Reid SA, et al.: The effect of simulated school load carriage configurations on shoulder strap tension forces and shoulder interface pressure. Appl Ergon, 2005, 36: 199-206. [Medline] [CrossRef]

13) Raine S, Twomey LT: Head and shoulder posture variations in 160 asymptomatic women and men. Arch Phys Med Rehabil, 1997, 78: 1215-1223. [Medline] [CrossRef]

14) Kim K, Kim CJ, Oh DW: Effect of backpack position on foot weight distribution of school-aged children. J Phys Ther Sci, 2015, 27: 747-749. [Medline] [CrossRef]

15) Oh JH, Choi SN: Effects of the length of schoolbag string on gait posture. J Sport Leis Stud, 2007, 30: 619-629.

16) Stuempfle KJ, Drury DG, Wilson AL: Effect of load position on physiological and perceptual responses during load carriage with an internal frame backpack. Ergonomics, 2004, 47: 784-789. [Medline] [CrossRef]

17) Lucas GN: Backpacks in children. 2011.

18) Bobet J, Norman RW: Effects of load placement on back muscle activity in load carriage. Eur J Appl Physiol Occup Physiol, 1984, 53: 71-75. [Medline] [CrossRef]

19) Chow DH, Ou ZY, Wang XG, et al.: Short-term effects of backpack load placement on spine deformation and repositioning error in schoolchildren. Ergonomics, 2010, 53: 56-64. [Medline] [CrossRef]

20) Grimmer K, Dansie B, Milanese S, et al.: Adolescent standing postural response to backpack loads: a randomised controlled experimental study. BMC Musculoskelet Disord, 2002, 3: 10. [Medline] [CrossRef]

21) Singh T, Koh M: Lower limb dynamics change for children while walking with backpack loads to modulate shock transmission to the head. J Biomech, 2009, 42: 736-742. [Medline] [CrossRef]

22) Golriz S, Walker B: Backpacks. Several factors likely to influence design and usage: a systematic literature review. Work, 2012, 42: 519-531. [Medline]

23) Joseph S, Sengupta A: Effect of backpack carriage position on physiological cost and subjective responses of university students. Adv Phys Ergonomics Hum Factors Part II. 2014, 15: 85.

24) Frank E, Stevenson JM, Stothart P: The effect of load placement on static posture and reaction forces in youth. Med Sci Sports Exerc, 2003, 35: S21. [CrossRef] 